\title{
Propostas de melhorias no processo de logística reversa: um caso do Solado PVC
}

\author{
Carlos Eduardo da Silva ${ }^{1}$ \\ Dusan Schreiber ${ }^{2}$ \\ Vanessa Theis $^{3}$
}

\begin{abstract}
Resumo
O objetivo deste artigo foi analisar e propor melhorias em relação às práticas de logística reversa relacionadas ao produto de solado em PVC comercializado pela BETA. Trata-se de uma pesquisa de cunho qualitativo, com uso de entrevista semiestruturada e observação não participante. Cumpre destacar que, a empresa está buscando a redução de despesas e deseja reaproveitar ao máximo os resíduos do processo de produção, bem como devoluções de clientes. No entanto, na análise realizada constatou-se que muitos colaboradores que estão envolvidas no processo de logística reversa, não estão capacitadas para verificar a melhor oportunidade ou não possuem solução para aplicação deste procedimento, ou por falta de conhecimento ou falta de recursos oferecidos pela empresa. Contudo, os gestores da BETA buscam reforçar a logística reversa em seu atual modelo de gestão.
\end{abstract}

Palavras-chave: Logística Reversa; Meio Ambiente; Resíduos; Matéria-Prima; Reciclagem.

\footnotetext{
Bacharel em Administração de Empresas pela Universidade Feevale Universidade Feevale. Brasil. cadusilvacs@hotmail.com

2 Doutor em Administração de Empresas pela UFRGS. Universidade Feevale. Brasil. ORCID: https://orcid.org/0000-0003-4258-4780 | dusan@feevale.br

3 Doutora em Qualidade Ambiental pela Universidade Feevale. Universidade Feevale. Brasil. ORCID: https://orcid.org/0000-0002-51007574 | vanessat@feevale.br
}

Como citar:

Silva, C. E. da, Schreiber, D., \& Theis, V. (2020). Propostas de melhorias no processo de logística reversa: um caso do Solado PVC. Revista Inovação, Projetos e Tecnologias, 8(1), 109-118. https://doi.org/10.5585/iptec.v8i1.17287 


\begin{abstract}
The purpose of this article was to analyze and propose improvements in relation to the reverse logistics practices related to the PVC sole product sold by BETA. It is a qualitative research, using semi-structured interviews and non-participant observation. It should be noted that, the company is seeking to reduce expenses and wishes to reuse as much as possible the waste from the production process, as well as customer returns. However, in the analysis carried out it was found that many employees who are involved in the reverse logistics process, are not able to verify the best opportunity or do not have a solution to apply this procedure, either due to lack of knowledge or lack of resources offered by the company. However, BETA managers seek to reinforce reverse logistics in their current management model.
\end{abstract}

Keywords: Reverse Logistics; Environment; Waste; Feedstock; Recycling.

\title{
1 Introdução
}

Os impactos ambientais, tais como o aquecimento global, poluição e desmatamento, tem motivado a sociedade a questionar as ações desenvolvidas pelas organizações que afetam o meio ambiente. Esta situação tem exigido das empresas uma busca cada vez maior pelo equilíbrio entre o desenvolvimento econômico e o sustentável, fazendo com que as mesmas passem a aderir a práticas que reduzam os impactos causados a natureza para garantir sua permanência no mercado (Barbieri, 2017; Sánchez, 2015).

Neste viés a adoção da logística reversa possibilita a redução do impacto ambiental, bem como auxilia na adequação de organizações à Política Nacional de Resíduos Sólidos, publicada em Agosto de 2010 na Lei n. 12.305 (2010), que institui a corresponsabilidade pelos resíduos entre o poder público, população, fabricantes e comerciantes quanto à disposição dos produtos recicláveis descartados no país. Não é mais possível ignorar os efeitos nocivos advindos da falta de práticas ambientais e da saturação de recursos naturais pelos sistemas produtivos. De modo a minimizar tais efeitos, a logística reversa pode ser utilizada como um instrumento competitivo e facilitador ao desenvolvimento de processos de recuperação de materiais (Leite, 2009).

Sendo assim, o objetivo deste artigo foi analisar e propor melhorias em relação às práticas de logística reversa relacionadas ao produto de solado em PVC comercializado pela BETA. Ressalta-se que a BETA está buscando na logística reversa uma forma de melhorar seus processos organizacionais, com o propósito de realizar a destinação correta destes materiais, minimizando as perdas por meio dos fluxos reversos.

Cumpre destacar que, no início deste estágio a empresa vendia seus materiais comprometidos para a sucata e, no momento em que percebeu a relevância destes elementos, resolveu investir em novas soluções para o reaproveitamento, a fim de usufruir para geração de uma nova matéria prima secundária. Em termos práticos, com esta pesquisa, espera-se contribuir de forma positiva para a gestão da logística reversa, tanto na BETA, como para as demais empresas que ainda não possuem essa metodologia, no sentido de construir e conscientizar a sociedade que devemos nos preocupar com o futuro de nosso ecossistema.

De modo a atingir o objetivo do estudo, optou-se pelo delineamento metodológico constituído de uma pesquisa qualitativa, a partir do estudo de caso em uma organização industrial. A coleta de dados empíricos ocorreu através de observação não participante e entrevistas semiestruturadas, em atendimento à recomendação de triangulação de dados em estudos de caso. Além desta introdução, este estudo contém uma revisão bibliográfica sobre logística reversa, detalhamento do delineamento metodológico, e, por fim, são apresentadas as considerações finais. 


\section{Logística reversa}

A intensiva exploração dos recursos naturais e o avanço do consumismo acentuaram as atenções sobre os impactos negativos ao meio ambiente. A fim de contribuir para essa temática, foram concebidas diferentes ferramentas, métodos e tecnologias, bem como foram realizados estudos e pesquisas, que resultaram em propostas de implantação, em organizações, de soluções, que possam economizar recursos e evitar a extração desordenada. Frente a isto, Pires (2004) e Barbieri e Dias (2002) destacam a necessidade das organizações em revisar suas práticas e políticas, de modo a viabilizar o desenvolvimento sustentável, evidenciando alternativas de oportunidades que podem surgir a partir da revisão de atuais modelos de negócio, bem como propiciar a constituição de vantagem competitiva.

Dentre as alternativas destaca-se a Logística Reversa (LR), que consta na Política Nacional de Resíduos Sólidos (PNRS), Lei n. 12305 (2010), no Brasil e pode contribuir, de forma relevante, para a redução dos impactos negativos ao meio ambiente. De acordo com a PNRS, a Logística Reversa é o instrumento de desenvolvimento econômico e social caracterizado por um conjunto de ações, procedimentos e meios destinados a viabilizar a coleta e a restituição dos resíduos sólidos ao setor empresarial. A finalidade deste instrumento consiste no reaproveitamento de resíduos em seu ciclo ou em outros ciclos produtivos e a destinação do rejeito de forma ambientalmente adequada.

Apontada por Donato (2008) como a área da logística responsável pelo retorno de materiais ao seu ciclo produtivo, a logística reversa reinsere materiais reaproveitados à determinada cadeia produtiva. Na mesma linha, Dias (2005) afirma que a logística reversa contribui para a construção de uma imagem sustentável perante os clientes. Ainda segundo este autor, a logística reversa possui a capacidade de ampliar as relações de parcerias entre os participantes da cadeia produtiva, bem como habilitar vantagens mútuas. No que tange as relações de parcerias entre os participantes da cadeia produtiva, comentada por Dias (2005), autores como Vilela e Demajorovic (2013) também destacam que a logística reversa demanda envolvimento de todos os elos de uma cadeia de suprimento em torno de um conceito principal - o ciclo de vida de produtos.

Complementado as assertivas acima indicadas, Vilela e Demajorovic (2013) tipificam a logística reversa em fechada e aberta. Ambas trabalham o fluxo reverso do material, mas na logística aberta o fluxo reverso pode formar novas cadeias de suprimento; já na fechada a mesma cadeia que gerou o resíduo realiza o fluxo reverso, reaproveitando e reinserindo o material recuperado em seu ciclo produtivo. Como fluxo aberto, pode-se citar Valle e Souza(2014), que destaca que muitas empresas destinam os resíduos para associações o que torna acessível para ambos. A Logística Reversa também estimula a realização de ações que recuperem o valor do resíduo sólido por meio da reutilização, reparação ou reciclagem, e subsequentemente incorporando-o a um novo ciclo produtivo, gerando benefícios principalmente nas esferas ambientais e econômicas (Hernández, Martins \& Castro, 2012; Oliveira, Souza, Silva, \& Silva, 2014; Vilela \& Demajorovic, 2013;).

Estudo realizado por Craco, Remussi, Biegelmeyer e Motta (2014) sobre logística reversa, como estratégia de fidelização, revela que esta pode contribuir, também, para a melhoria do desempenho, competitividade e imagem corporativa. Corroborando as constatações dos autores já citados, Barbieri e Dias (2002) destacam que as organizações também devem reconhecer na logística reversa uma oportunidade estratégica, capaz de alterar seu modo de produzir, ao mesmo tempo em que reduz os danos ambientais. Tal assertiva, também é corroborada por Bowersox e Closs (2007) que colocam a logística reversa como um elemento de desenvolvimento sustentável e planejamento organizacional. Nesta mesma perspectiva Leite (2009) afirma que a logística reversa minimiza os efeitos nocivos ao meio ambiente.

A área da logística empresarial é a responsável pelo planejamento de todo o controle dos 
fluxos de movimentação dos bens de modo integrado, que engloba, também, os aspectos como transporte, gerenciamento de estoque e armazenagem. Logo, se alguma etapa do processo não sair conforme planejado, pode afetar o restante do percurso. Já a logística reversa segue o caminho inverso, iniciando em canais de distribuição, de forma oposta ao fluxo original. Esse processo pode ser incorporado à própria empresa que gerou o resíduo ou ser terceirizado (Aldmaier \& Sellitto, 2007; Sellitto, Kadel, Borchadart, Pereira, \& Domingues, 2013).

Ao passar pelo processo de Logística Reversa, o produto ou o resíduo precisa ser classificado, selecionado e inspecionado, a fim de identificar os valores ainda presentes, facultando assim a melhor forma de sua disposição. Depois de analisado, e se condições adequadas, este pode ser encaminhado diretamente para o reuso, revenda ou redistribuição. Caso contrário, o mesmo poderá ser destinado à reparação, renovação, recuperação, reciclagem ou incineração (Brito \& Dekker, 2003). É válido ressaltar que a maioria dos materiais reciclados se modifica do original não podendo ser utilizado para constituir o mesmo produto (Razzolini Filho \& Berté, 2013).

Importante ressaltar que, conforme Ballou (2007), o nível de serviço logístico pode ser analisado através de uma auditoria diretamente com o cliente, consultando sobre o desempenho e estabelecendo um padrão de satisfação. Nestas condições pode-se verificar se o nível está adequado aos padrões dos clientes ou quais mudanças devem ocorrer, ajudando a conduzir o serviço a um patamar satisfatório para todos.

Além de medidas legais, fatores econômicos e ambientais, a pressão dos consumidores figura dentre os principais fatores motivadores para a implementação da logística reversa (Oliveira et al., 2014). No quesito econômico, os ganhos decorrem da recuperação de valor do resíduo para a sua reutilização e da redução dos custos com atividades para a sua eliminação. No aspecto ambiental destacam-se, ainda, a redução do uso dos recursos naturais não renováveis, a minimização de emissões atmosféricas, a redução da poluição e a disposição final adequada de resíduos perigosos e não perigosos (Brito \& Dekker, 2003; Gardin, Figueiró, \& Nascimento, 2010).

Apesar de não estar entre os principais fatores de implementação, Souza e Fonseca (2009) acreditam que a logística reversa também é relevante no quesito social, pois os grandes beneficiados por esse processo é a sociedade. Um dos resultados deste processo é a diminuição do volume de lixo em aterros sanitários e industriais, o que contribuiu para uma redução da contaminação dos lençóis freáticos e principalmente reduzindo as chances de proliferação de doenças para a população.

Todavia, Oliveira et al. (2014) destacam que para se desenvolver e poder gerar benefícios, além de contribuir para o desenvolvimento sustentável, a logística reversa precisa ser estimulada, preferencialmente por meio de incentivos governamentais. Além disso, as organizações ainda encontram barreiras a esta prática, como falta de investimentos em infraestrutura e conhecimento reduzido por parte dos profissionais da área. Mesmo assim, Brito e Dekker (2003) consideram que a Logística Reversa assumiu um papel de grande relevância na contribuição ao ciclo do desenvolvimento sustentável, gerando principalmente benefícios econômicos e ambientais. A afirmação é corroborada por Vilela e Demajorovic (2013) ao indicar, que dificilmente uma empresa poderá atuar sustentavelmente através de produtos, processos, tecnologias e modelos de negócios ambiental e socialmente adequados, sem antes tratar tal tema ao longo de toda a sua cadeia produtiva.

Em síntese, é possível afirmar que a logística reversa vem a ser uma forma eficiente de promover o descarte controlado, além de ser uma ferramenta estratégica para a diminuição da degradação ambiental, capaz de trazer alterações positivas à economia e ao incremento de receitas, pela geração de novos postos de trabalho, novos produtos e novas formas para a redução de impactos 
negativos sobre o meio ambiente (Barbieri \& Dias, 2002; Brito \& Dekker, 2003; Bowersox \& Closs, 2007; Gardin, et al., 2010; Leite, 2009).

\section{Metodologia}

Os autores optaram, na concepção do delineamento metodológico, pelo estudo de caso, por apresentar melhor aderência ao objetivo e às questões que nortearam a concepção da pesquisa. Em atendimento à recomendação de autores que versam a temática do estudo de caso, com destaque a Yin (2015), foi realizada a triangulação de dados empíricos coletados. A triangulação de dados permite ao pesquisador cruzar informações obtidas por diferentes instrumentos de coletas de dados.

Com este propósito a triangulação dos dados foi complementada com os dados que emergiram a partir da consulta à literatura sobre logística reversa, os dados empíricos coletado por meio de entrevistas e a observação não participante, através de uma visita às instalações da empresa. Foram realizadas sete entrevistas sendo as mesmas gravadas e transcritas. O roteiro utilizado na entrevista pode ser conferido na Figura 1.

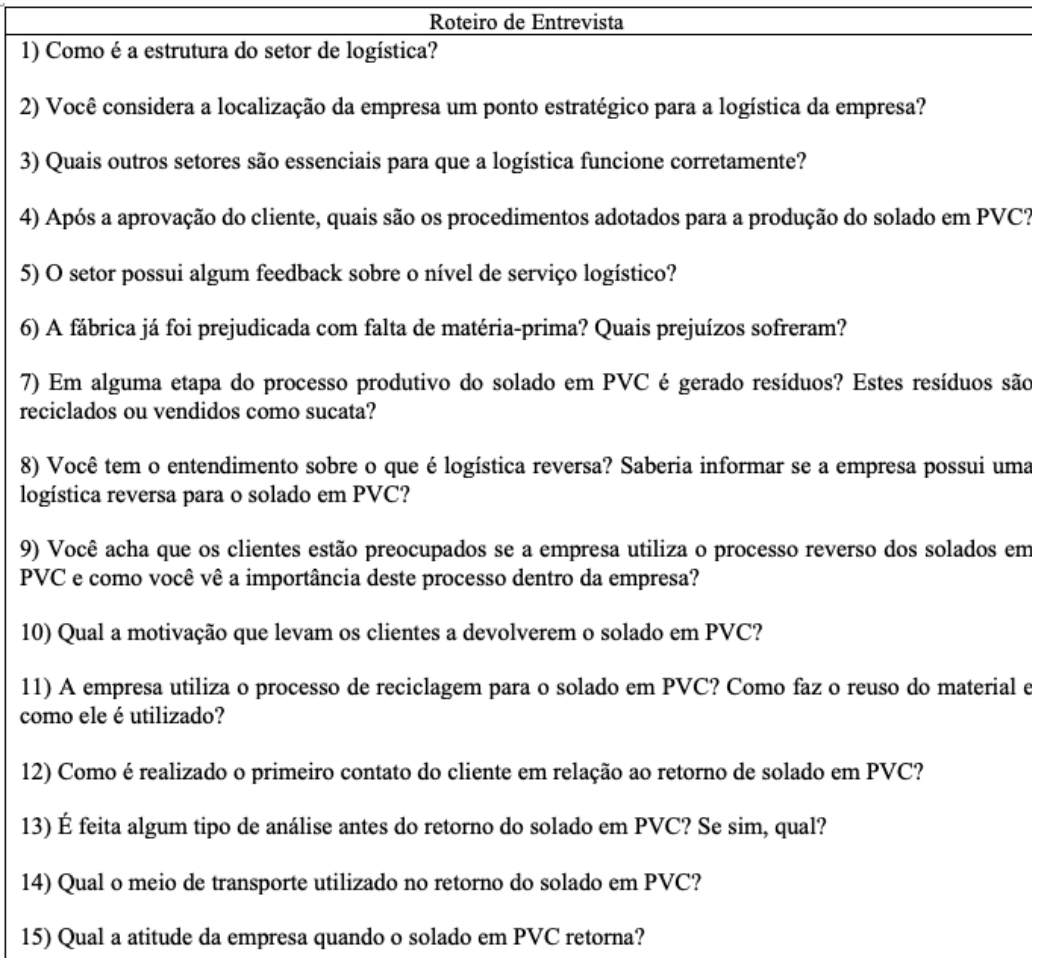

\section{Figura 1: Roteiro da Entrevista}

Fonte: Dados da pesquisa.

A empresa à qual se refere este estudo, foi fundada em janeiro de 2012, na cidade de Novo Hamburgo, e, por questões de confiabilidade de dados, será denominada BETA. A empresa trabalha com a industrialização e comercialização dos injetados. Por ser uma empresa de pequeno porte, todas as operações passam pela supervisão dos dois diretores, e, por isto, realizou-se entrevista com estes. Ademais, foram entrevistados outros cinco profissionais. A Figura 2 revela o perfil dos profissionais entrevistados. 


\begin{tabular}{|c|c|c|}
\hline Entrevistados & Cargo & Tempo na Empresa \\
\hline E1 & Diretor & 7 Anos \\
\hline E2 & Gerente produtiva & 7 Anos \\
\hline E3 & Assistente administrativo & 7 Anos \\
\hline E4 & Assistente de PCP & 1 Ano \\
\hline E5 & Encarregado logística & 3 Anos \\
\hline E6 & Assistente de compras & 2 Anos \\
\hline E7 & Auxiliar de produção & 2 Anos \\
\hline
\end{tabular}

Figura 2: Identificação dos sujeitos da pesquisa

Fonte: Dados da pesquisa.

Os dados foram analisados por meio da análise de conteúdo, proposta por Bardin (2011). Segundo a autora, este método consiste em procedimentos para levantar inferências válidas a partir do texto, buscando classificar palavras, frases, ou mesmo parágrafos em categorias de conteúdo. Ressalta-se que as categorias de análise podem ser criadas a priori ou a posteriori, isto é, a partir da teoria ou após a coleta de dados. No caso deste artigo, as categorias foram criadas a posteriori, sendo elas: i) Apresentação das atividades e do processo de logística reversa; e, ii) Propostas de melhorias na logística reversa da BETA.

\section{Resultados e análise}

Constatou-se que os setores que mais contribuem para a logística são compras, PCP e produção. Após a aprovação do solado, é necessário a solicitação do comercial, para a produção emitir um formulário com a amostra, especificando espessura e cor para a aprovação do cliente. Segundo E3 e E5, o processo de produção passa pelo PCP e após é gerada a ordem de produção. A fábrica solicita para a logística o PVC, para iniciar o processo de mistura para obter a cor desejada. A fábrica entrega o produto acabado no setor de logística, e este faz o despacho conforme orientação do comercial.

Contudo, E1, E2, E3, E4 sinalizam que a fábrica já foi prejudicada com a falta de matéria prima, gerando falta de credibilidade junto aos clientes, cancelamentos de pedidos, atrasos na entrega e diminuição no faturamento diário. $\mathrm{Na}$ empresa em análise, a logística é encarregada por todas as entradas e saídas, tornando-se importante para não gerar faltas ou sobras no estoque, que ressalta que se os processos não forem bem planejados, afetam o restante do percurso.

Com relação aos resíduos gerados, E1, E3 e E4 relatam que alguns são descartados como sucatas e outros são reciclados. Segundo E2, E5 e E6 no processo de produção, são geradas sobras de Plástico (PVC) que são direcionadas para o setor de reciclagem, onde transformam-se em material para ser utilizado novamente na produção. E6 informa que no processo também existe uma rebarba chamada de "fita", conforme demonstra a Figura 3, que igualmente é transformada em um novo material. Estes resíduos são gerados no processo de injeção, e, após a moagem serão reaproveitados em outros produtos. 


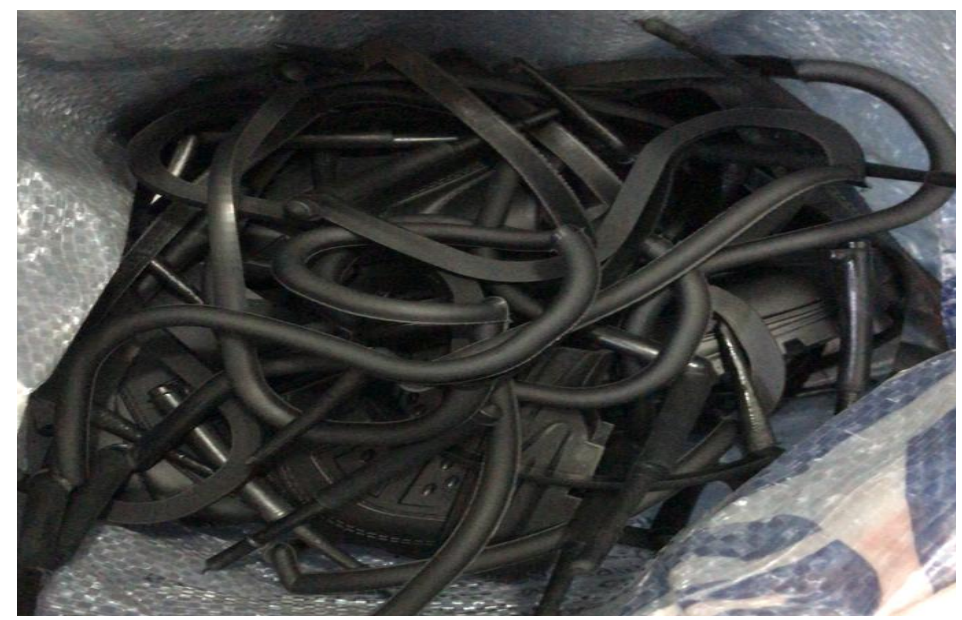

Figura 3: Resíduos gerados pela fábrica

Fonte: Dados da pesquisa.

De acordo com Razzolini Filho e Berté (2013), a modificação com base na reciclagem torna o material diferente do original podendo apenas ser utilizado em novos produtos. No caso da BETA, esta transformação torna a matéria prima secundária, podendo ser aproveitado para fabricação de alguns produtos. Segundo E1 e E7, em alguns casos o PVC é reutilizado para novos solados, já E6 informa que é utilizado na fabricação de matéria prima semiacabada.

De acordo com E5, todos os produtos são produzidos somente após aprovação do cliente. A devolução ocorre quando há um erro (cor, escrita) que não tenha sido percebida pelo setor de qualidade dentro da fábrica. A respeito desta questão, E6 e E7 sinalizam que a BETA não realiza nenhuma pesquisa de qualidade ou satisfação após o recebimento dos pedidos, a fim de entender melhor sobre quais expectativas do cliente não foram atendidas. E1 e E6 descrevem que a devolução do material também é feita quando o cliente entende que deve reciclar o material, para não jogar na natureza e por já não serem mais úteis para seu consumo.

Neste sentido, os entrevistados E1 e E2 informam que logística reversa é o meio mais sustentável adotado para o reaproveitamento dos resíduos para uma nova matéria prima, sendo que a empresa adota esse sistema para as sobras do PVC. E6 e E7 ressaltam que os clientes estão preocupados com o destino do solado em PVC, E7 vê a importância desse processo como benefício ao meio ambiente, já o E6 considera vantagem para uma maior competitividade.

Constata-se que os relatos dos entrevistados vão ao encontro dos conceitos expostos por Donato (2008), Dias (2005), Craco et al. (2014), os quais entendem que a logística reversa contribui para a construção de uma imagem sustentável perante os clientes, além de ser uma estratégia de fidelização. Contudo, E3 sinaliza que a logística reversa da empresa ainda é deficiente e apresenta inúmeros aspectos a serem melhorados, devido às informações desencontradas e o retrabalho em algumas etapas.

Conforme E1 e E3 normalmente o cliente pede se a BETA dispõe de algum tipo de serviço relacionado a descarte ou reciclagem. O primeiro contato é diretamente com o comercial, ou seja, vendedor que possui aquela carteira de cliente. O setor comercial verifica e analisa a solicitação do cliente e segundo E6 a área comercial emite uma Autorização de Retorno de Mercadoria, para assim o setor de expedição saber do que se trata.

E3 ainda discorre que, a partir do momento que o cliente envia os produtos, isso passa a ser uma preocupação para a empresa, para fazer o processo adequadamente. E1 informa que muitos clientes estão preocupados com o processo de reaproveitamento e sustentabilidade do material já produzido, o problema é a desvantagem no custo de transporte para o retorno deste material. Em 
contrapartida, Leite (2009) destaca que a reutilização ajuda o planeta, visto que diminui o consumo da matéria prima e minimiza os efeitos nocivos ao meio ambiente.

De acordo com E3 e E5 o transporte do material é feito com o carro da empresa ou transportadoras, dependendo do peso e da localização do cliente. Conforme E1 e E6, se faz a avaliação do produto que retornou do cliente para fazer uma seleção do material, se possui falhas ou não, para em seguida ser enviado para a reciclagem ou descarte, processo corroborado por Brito e Dekker (2003), visto que é essencial identificar os valores ainda presentes nos resíduos.

\subsection{Propostas de melhorias na logística reversa da beta}

$\mathrm{Na}$ busca por melhorias sobre as análises realizadas e embasando-se nas bases conceituais levantadas, destaca-se que Pires (2004) e Barbieri e Dias (2002) enfatizam a necessidade das organizações revisar suas práticas e políticas, de modo a viabilizar o desenvolvimento sustentável, evidenciando alternativas de oportunidades que podem surgir a partir da revisão de atuais processos e modelos de negócios. Desta maneira sugere-se que a BETA reestruture os setores envolvidos no processo de logística reversa, tornando-os mais responsáveis pelas tarefas e rotinas diárias, a fim de fortalecer a comunicação interna e extinguir o desencontro de informações e o retrabalho.

$\mathrm{Na}$ revisão teórica, Ballou (2007) aconselha uma avaliação sobre o serviço prestado do fornecedor ao cliente, com o propósito de verificar os níveis de satisfação quanto aos serviços de logística e qualidade do produto. A BETA poderia contatar e auditar o cliente sobre o processo realizado, verificando a satisfação e se o nível de serviço está adequado às expectativas. Nesta etapa, devem estar envolvidos os setores comercial e logística, a fim de traçar uma linha eficiente de comunicação das informações trazidas pelos clientes e, consequentemente às adequando aos novos parâmetros de qualidade e satisfação.

Em análise do retorno sobre os motivos das devoluções do solado em PVC, pôde se constatar que uma forma de melhorar o fluxo da logística reversa e torná-la mais eficiente é a utilização de toda sua capacidade, ou seja, conforme Valle e Souza (2014), a BETA teria a capacidade de melhorar sua estrutura organizacional, influenciando diretamente no planejamento estratégico, integrando o processo sistêmico e aproveitando recursos e oportunidades. Com relação a este tópico, a BETA poderia seguir as recomendações de Dias (2005), Vilela e Demajorovic (2013), no sentido de ampliar as relações de parcerias entre os participantes da cadeia produtiva, a fim de habilitar vantagens mútuas até mesmo com a utilização da logística aberta, onde fluxo reverso pode formar novas cadeias de suprimentos.

Analisando o conteúdo informado sobre os atores envolvidos no processo de logística reversa, dependendo da quantidade e volumes que serão devolvidos pelo cliente, se torna desvantajoso o retorno do material, pois o custo de transporte se tornaria alto e inviável para a BETA. Uma alternativa, conforme sinalizado por Valle e Souza (2014), seria destinar os resíduos para associações parceiras mais próximas ao cliente. Esta seria uma opção mais acessível para a BETA nos casos em que as devoluções ocorressem em pequenas quantidades e a localização do cliente fosse distanciada da sede.

\section{Considerações finais}

O presente estudo objetivou analisar e propor melhorias em relação às práticas de logística reversa relacionadas ao produto de solado em PVC comercializado pela BETA. A partir da análise dos dados coletados com os entrevistados, verificou-se que a BETA já realiza a logística reversa no seu produto, contudo ainda existem alguns aspectos que podem ser melhorados, principalmente no 
que diz respeito na relação comercial com os clientes e o fluxo de informações.

Ressalta-se que a BETA possui como matéria prima principal o PVC, que é uma grande vantagem para utilização no processo de reciclagem, por possuir métodos mais simples para o reaproveitamento e utilização em novos produtos. A necessidade de reutilizar e reciclar este material pode ser uma alternativa para as empresas que usufruem deste material.

No tocante às limitações da pesquisa, destacam-se a opção metodológica, de estudo de caso único, e a coleta de evidências, realizada por meio de entrevistas, visto que a amplitude das respostas depende do conhecimento e da experiência tanto do entrevistado como dos pesquisadores com provável viés e influência na interpretação das evidências que emergiram do processo de análise. Outro fator limitante refere-se à impossibilidade de generalização analítica dos resultados obtidos, estando restrita à realidade investigada.

Contudo, salienta-se que o estudo traz importantes contribuições à compreensão da específica realidade organizacional, que facultou a compreensão do processo de logística reversa, estimulado pela perspectiva de aprimoramento do desempenho e da competitividade organizacional. Os resultados advindos deste estudo, mesmo sendo um estudo de caso único, comprovam que diante do desafio de produzir e preservar, a logística reversa pode viabilizar soluções além da prática ambiental, oportunizando evidenciar também novos modelos de negócios às organizações envolvidas.

\section{Referências}

Adlmaier, D., \& Sellitto, M. A. (2007). Embalagens retornáveis para transporte de bens manufaturados: um estudo de caso em logística reversa. Production, 17(2), 395-406.

Ballou, R. H. (2007). Gerenciamento da cadeia de suprimentos/logística empresarial. Porto Alegre: Bookman.

Barbieri, J. C. (2017). Gestão ambiental empresarial. Editora Saraiva.

Barbieri, J. C., \& Dias, M. (2002). Logística reversa como instrumento de programas de produção e consumo sustentável. Tecnologias. São Paulo, 77, 58-69.

Bardin, L. (2011). Análise de conteúdo. São Paulo, SP: Edições 70.

Bowersox, D. J., \& Closs, D. J. (2007). Logística empresarial: o processo de integração da cadeia de suprimento. 1. ed. São Paulo: Atlas.

Brito, M., \& Dekker, R. (2003). A framework for reverse logistics. ERIM Report Series Research In Management, n. ERS-2003-045-LIS, Erasmus Research Institute of Management (ERIM). Disponível em: <https://dspace.ubib.eur.nl/retrieve/439/ERS-2003-045-LIS>. Acesso em 5 de agosto de 2015.

Caxito, F. (2014). Logística: um enfoque prático. $2^{\circ}$ ed. São Paulo: Saraiva.

Craco, T., Remussi, R., Biegelmeyer, U., \& Motta, M. (2014) Logística reversa usada como estratégia de fidelização. Revista Escola de Negócios, 2(1), 215-224.

Dias, J. C. Q. (2005). Logística global e macrológica. Lisboa: Síbalo.

Donato, V. (2008). Logística Verde. Rio de Janeiro: Ciência Moderna.

Gardin, J. A. C., Figueró, P. S., \& Nascimento, L. F. (2010). Logística reversa de pneus inservíveis: discussões sobre três alternativas de reciclagem para este passivo ambiental. Revista Gestão e Planejamento, Salvador, 11(2), 232-249.

Hernández, C. T., Marins, F. A. S., \& Castro, R. C. (2012). Modelo de Gerenciamento da Logística Reversa. Gestão \& Produção, São Carlos, 19(3), 445-456. 
Leite, P. R. (2009). Logística Reversa: Meio Ambiente e Competitividade. 2. ed. São Paulo: Pearson Prentice Hall.

Lei n. 12.305, de 2 de agosto de 2010 (2010). Institui a Política Nacional de Resíduos Sólidos (PNRS); altera a Lei no 9.605, de 12 de fevereiro de 1998; e dá outras providências. Disponível em:< http:/www.planalto.gov.br/ccivil_03/_ato2007-2010/2010/lei/112305.htm>. Acesso em: 31 agosto 2015.

Oliveira, G. C., Souza, M. T. S., Silva, D., \& Silva, L. A. (2014). Avaliação das vantagens ambientais e econômicas da implantação da logística reversa no setor de vidros impressos. Ambiente e Sociedade, São Paulo, 17(3), 199-220.

Pires, S. R. I. (2004). Gestão da cadeia de suprimentos: conceitos, estratégias, práticas e casos. São Paulo: Atlas.

Razzolini Filho, E., \& Berté, R. (2013). O reverso da logística e as questões ambientais no Brasil. Curitiba: InterSaberes.

Sánchez, L. E. (2015). Avaliação de impacto ambiental. Oficina de Textos.

Sellitto, M. A., Kadel J., N., Borchardt, M. Pereira, G. M., \& Domingues, J. (2013). Coprocessamento de cascas de arroz e pneus inservíveis e logística reversa na fabricação de cimento. Ambiente e Sociedade, São Paulo, 16(1), 141-162.

Souza, S. F., \& Fonseca, S. U. L. da. (2009) Logística reversa: oportunidades para redução de custos em decorrência da evolução do fator ecológico. Revista Terceiro Setor. São Paulo. 3(1).

Valle, R., \& Souza, R. G. (2014) Logística reversa: processo a processo. São Paulo: Atlas, .

Vilela, A.; Demajorovic, J. (2013). Modelos e ferramentas de gestão ambiental: desafios e perspectivas para as organizações. 3. ed. São Paulo: Editora SENAC.

Yin, R. K. (2015). Estudo de caso: planejamento e método. Edition-Porto Alegre: Bookman. 